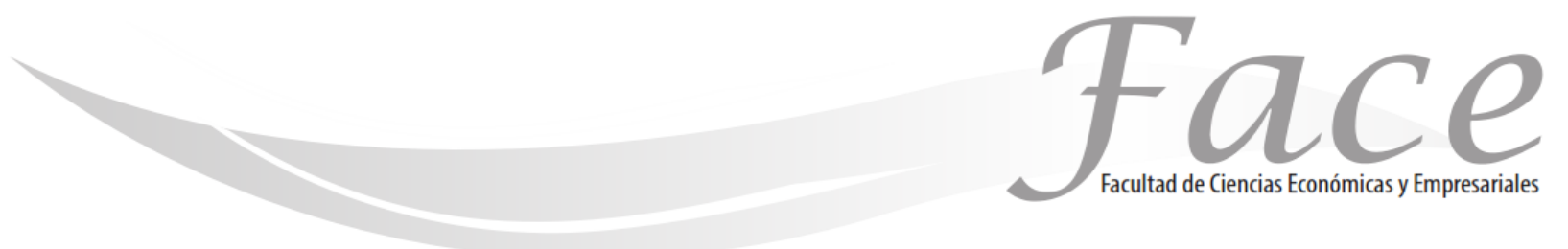

ISSN Impreso: 1794-9920

ISSN Electrónico: 2500-9338

Volumen $19-\mathrm{N}^{\circ} 2$

Año 2019

Págs. $51-62$

(c) (1) $\Theta \Theta$

\title{
REMESAS Y CREACIÓN DE MICRO EMPRESAS EN HUANDACAREO, MICHOACÁN
}

\author{
Alicia Melgarejo Terrazas * \\ ORCID: https://orcid.org/0000-0001-5758-8368 \\ María de la Luz Martín Carbaja|** \\ ORCID: https://orcid.org/0000-0001-5758-8368
}

Fecha de Recepción: Junio 14 de 2019

Fecha de Aprobación: Octubre 1 de 2019

\section{Resumen:}

El uso productivo de las remesas enviadas a Huandacareo, Michoacán, por individuos que emigran a los Estados Unidos no ha contribuido significativamente al crecimiento económico de esa ciudad. Sin embargo, ha beneficiado económicamente a las familias que han creado microempresas en la localidad y que han empleado a un buen número de trabajadores distintos de esas familias. Para diseñar y llevar a cabo el estudio se realizó un recuento de los negocios ubicados en el centro de la ciudad de Huandacareo, que utilizaron o utilizaron remesas para su establecimiento y operación. Se encontró que, de 152 empresas, solo el cuatro por ciento usa remesas y, por lo tanto, las historias de vida se tomaron como un método de investigación. Se encontró que es más probable que los migrantes retornados trabajen por cuenta propia que los no migrantes, y que tanto los ahorros de retorno como la frecuencia de los cambios de trabajo durante la migración aumentan la probabilidad de que los migrantes retornados trabajen por cuenta propia. Estos hallazgos sugieren que (a) la migración de retorno puede ayudar a revitalizar las economías rurales y aliviar la pobreza en las áreas menos desarrolladas de Michoacán; y (b) el capital repatriado es un factor clave y estimulante para promover las actividades empresariales.

Palabras clave: crecimiento económico, retorno de migrantes, dependencia de remesas, uso productivo de remesas, creación de micro y pequeñas empresas.

\footnotetext{
*Egresada de la Facultad de Economía "Vasco de Quiroga" Universidad Michoacana de San Nicolás de Hidalgo. México. Contacto: amelgarejo@fevaq.net y t_aliz@hotmail.com.

** Profesora e investigadora. Facultad de Economía "Vasco de Quiroga", Universidad Michoacana de San Nicolás de Hidalgo-México. Contacto Imartin@fevaq.net
} 


\title{
RACES AND CREACIÓN OF MICRO COMPANIES IN HUANDACAREO, MICHOACÁN
}

\begin{abstract}
:
The productive use of remittances sent to Huandacareo, Michoacán by individuals who emigrate to the United States has not contributed significantly to the economic growth of that city. However, it has benefited economically the families that have created microenterprises in the locality and that have employed a good number of workers other than those families. To design and carry out the study, a count was made of the businesses located in Huandacareo downtown, which used remittances for their establishment and operation. It was found that out of 152 companies, only four percent use remittances and, therefore, life histories were taken as a research method. It was found that returned migrants are more likely to be self-employed than nonmigrants, and that both return savings and the frequency of job changes during migration increase the likelihood of returning migrants working on their own. These findings suggest that (a) return migration can help revitalize rural economies and alleviate poverty in the less developed areas of Michoacán; and (b) repatriated capital is a key and stimulating factor to promote business activities.
\end{abstract}

Keywords: economic growth, return of migrants, remittances dependence, productive use of remittances, creation of micro and small businesses.

\section{RAÇAS E CRIAÇÃO DE MICRO EMPRESAS EM HUANDACAREO, MICHOACÁN}

\section{Resumo:}

O uso produtivo das remessas enviadas a Huandacareo, Michoacán por indivíduos que emigram para os Estados Unidos não contribuiu significativamente para o crescimento econômico dessa cidade. No entanto, beneficiou economicamente as famílias que criaram microempresas na localidade e empregaram um bom número de trabalhadores além dessas famílias. Para projetar e realizar o estudo, foram contadas as empresas localizadas no centro de Huandacareo, que usavam remessas para seu estabelecimento e operação. Constatou-se que das 152 empresas, apenas quatro por cento usam remessas e, portanto, as histórias de vida foram tomadas como método de pesquisa. Verificou-se que os migrantes retornados são mais propensos a trabalhar por conta própria do que os não migrantes, e que tanto a economia de retorno quanto a frequência das trocas de emprego durante a migração aumentam a probabilidade de os migrantes retornarem trabalhar por conta própria. Essas descobertas sugerem que (a) a migração de retorno pode ajudar a revitalizar as economias rurais e aliviar a pobreza nas áreas menos desenvolvidas de Michoacán; e (b) o capital repatriado é um fator essencial e estimulante para promover as atividades comerciais.

Palavras-chave: crescimento econômico, retorno de migrantes, dependência de remessas, uso produtivo de remessas, criação de micro e pequenas empresas. 


\section{INTRODUCCIÓN:}

La migración es una manifestación socioeconómica que se produce por la búsqueda constante de oportunidades para mejorar el nivel de vida de los migrantes y sus familias. De las remesas que ingresan a Michoacán, dos tercios se destinan al consumo, es decir, alimentos, salud, construcción y remodelación de viviendas, así como para la compra de bienes duraderos. Esto significa que las remesas se utilizan en menor medida para la inversión 0 para la creación de micro o pequeñas empresas; el PNUD Michoacán (2008) también considera que la construcción de viviendas también puede considerarse una inversión.

Se podría pensar que las remesas estimulan una mayor inversión en la educación primaria y secundaria para los hijos de los migrantes; pero, puede ser que se desaliente la inversión en educación superior, pues debido a factores psicológicos y/o culturales los individuos prefieren emigrar de la misma manera que lo hicieron sus padres. Esos dos factores influyen en el destino de las remesas debido al bajo nivel de escolarización de los habitantes de una localidad que hace que las decisiones de inversión productivas de las remesas se pospongan o no se realicen. En el caso de Huandacareo las inversiones en la creación de pequeñas empresas se realizan principalmente cuando los migrantes regresan de manera voluntaria, definitiva 0 indefinida, o debido a la deportación.

Ahora bien, Michoacán es uno de los principales receptores de remesas en México y éstas son una fuente de ingresos muy importante ya que se supone que las remesas promueven el desarrollo de las comunidades. En este sentido, vale la pena preguntar si ¿las remesas recibidas en Huandacareo tienen una influencia significativa en la economía y desarrollo de dicha localidad? Del mismo modo, si las remesas se utilizan principalmente en el consumo; pero, parte de estos se invierten en infraestructura y microempresas $i$ el uso que se da a las remesas en Huandacareo es productivo? Se presume que las remesas recibidas en Huandacareo tienen una influencia positiva en la economía local ya que los migrantes que regresan han creado micro y pequeñas empresas.
Después de esta introducción este artículo se divide en cinco partes. En la primera se establece una clasificación de las remesas y se esclarece si su uso es productivo. En la segunda sección se describe la migración del Estado de Michoacán, la importancia de las remesas para la economía nacional; la situación migratoria y el tipo de microempresas en Huandacareo y las remesas que ingresan a ese municipio. En la tercera parte se muestran los resultados de las historias de vida de cuatro empresarios que establecieron sus negocios con remesas y se efectúa un análisis de las mismas. Finalmente, la cuarta parte se establecen las conclusiones de la investigación.

\section{MARCO REFERENCIAL.} 1. Clasificación de las remesas y su
aprovechamiento

\subsection{Clasificación}

Es importante considerar la distinción de los tipos de remesas haciendo énfasis en las de inversión y capital para analizar su influencia en la localidad y el uso productivo de las mismas. Durand (1994) distingue tres tipos de remesas según su función: i) remesas como salarios, que los migrantes envían esporádicamente o frecuentemente a sus familias; ii) remesas como una inversión que se envían, principalmente, en los viajes de retorno de los migrantes, y que tienen como objetivo la compra de terrenos o la construcción de una casa; y, iii) las remesas como capital, cuyo propósito explícito es hacer una inversión productiva. Las remesas como inversión y como capital influyen favorablemente a nivel local al diversificar las actividades económicas y crear alternativas de trabajo (Fernández, 2013).

También Goldring (2004) identificó tres categorías diferentes de remesas: i) fondos familiares, que se emplean principalmente para cubrir gastos en alimentación, ropa, vivienda y para mejorar el acceso de las familias a los servicios de salud, educación y seguridad social; ii) remesas colectivas, enviadas por clubes de campo para 
proyectos comunitarios; y, iii) remesas comerciales, cuyo objetivo explícito es la inversión porque los migrantes están tratando de regresar a su lugar de origen.

Desde principios de este siglo, la cantidad de remesas que ingresaron a México se ha incrementado debido al aumento constante de trabajadores migrantes y la reducción en el costo del envío de remesas familiares. Este costo ha disminuido según el tipo de instrumentos financieros utilizados para enviar dinero. Por ejemplo, desde 1995 al menos, los migrantes prefieren usar los envíos a través de transferencias electrónicas. De hecho, si se toma el periodo 1995 a 2005 , el $80.5 \%$ de las transferencias de remesas familiares se realizó por este medio; mientras que en el lapso 2011-2015 fue de 97.3 por ciento, incluso durante 2016 - 2017, el $97.7 \%$ de las remesas familiares fueron transferencias bancarias electrónicas. En contraste, otras formas tradicionales de enviar dinero han perdido su validez en 27 años, como es el caso de las órdenes de pago y en efectivo o en especie, mientras que los cheques personales destinados a familiares en México han desaparecido.

Por el lado del costo del envío de remesas según la información de BBVA (2018) en el período 2003 - 2017 el costo del envío de 300 dólares estadounidenses a México disminuyó en promedio 9.10 dólares (10.19 en el período 2003-2007 dólares en el período 2008 - 2011 y \$ 7.42 en el período 2013 - 2017). Nótese que lo anterior es el costo que pagan los migrantes por el envío de remesas, por lo que se debe agregar la comisión que la persona que recibe el dinero en México debe pagar. Según el informe del Banco Mundial (2016) el costo promedio de envío de remesas en el mundo es del 8,0 por ciento, lo que puede significar un obstáculo para el desarrollo de los países de economías emergentes que reciben estos recursos. ${ }^{1}$

Así, las remesas han sido un paliativo para reducir la pobreza, es decir, para mejorar el nivel de vida de las familias, en particular las rurales. Para los fines de este

\footnotetext{
1 En el caso mexicano, existe una sucursal bancaria por cada 12 mil 160 habitantes. La Comisión Nacional de Bancos y Valores (CNBV) con datos reportados en el segundo trimestre de 2007 indica que había 39 instituciones bancarias con 8,717 sucursales a junio de 2007. Los cinco bancos en el país con la mayor cantidad de sucursales bancarias son: Distrito Federal (1,512); Estado de México (809); Jalisco (741); Nuevo León (678) y Veracruz (405).
}

estudio, se considerará la siguiente distinción para los tipos de remesas: inversión y capital, para analizar su afluencia en la localidad y su uso productivo, además, para el uso de remesas familiares también se toman en cuenta gastos tales como educación, ya que es una inversión para la formación profesional.

\subsection{Uso de remesas}

Las remesas no son un paquete homogéneo ya que existen diferentes conceptos para designarlas. Se ha señalado que van más allá de consideraciones estrictamente económicas. Levitt (1998) sugirió utilizar la noción de remesas sociales para observar los cambios culturales y las actividades sociales derivadas del fenómeno migratorio en las comunidades de origen; también Nichols (2002) ha utilizado el término remesas de tecnología para resaltar la relevancia del conocimiento y la tecnología agrícola que los migrantes transfieren a sus comunidades; además, Amuedo y Poso (2006) consideraron que el ahorro de los migrantes de retorno es otra forma de remesas; mientras que Fuentes (2010) documentó los cambios políticos relacionados con la migración, por lo que él las ha llamado remesas políticas y éstas cubren diferentes facetas: económica, social, cultural, tecnológica y política.

También se ha indicado que, además de su uso para el consumo, las remesas se utilizan para comprar diferentes bienes duraderos, incluidos lotes y viviendas, y se reduce la parte de las remesas que se utilizan para inversiones productivas 0 ahorros. A menudo remesas proporcionan el capital inicial para impulsar la formación de empresas familiares (Vega, 2012). Se considera uso productivo de las remesas las que se utilizan para la compra de bienes duraderos, la inversión en educación superior y la inversión en pequeñas empresas. Si bien las remesas son un flujo salarial esencial para el apoyo familiar y no un ahorro o ingreso adicional, pueden utilizarse para establecer negocios con el propósito de generar ganancias para el sustento familiar y seguir invirtiendo.

En Huandacareo, las remesas que se envían en forma de ahorro para migrantes e incluso aquellas que ingresan en el momento en que el migrante decide regresar, se invierten en remodelaciones, ampliaciones o construcción de casas, así como en negocios lucrativos que les 
proporcionan mayores ingresos e independencia laboral tales como tiendas de abarrotes, herrerías, fruterías, construcción de balnearios, taxis, salones de belleza, transporte público y servicios de Internet, entre otros.

Algunos de los estudios que se han realizado sobre migración y remesas coinciden en que más del $80 \%$ de las familias asignan el uso de las remesas al consumo e identifican esta variable como medio de vida, sin embargo, si el migrante tiene un empleo con ingresos más altos o prolonga su permanencia en Estados Unidos, aumenta la cantidad de remesas y, por lo tanto, la familia gasta menos en medios de subsistencia e invierte más en activos patrimoniales, activos productivos o educación (Corona, 2018).

Por ejemplo, en una investigación realizada en Cuautlancingo, Puebla, de abril de 2015 a septiembre de 2016, se realizó una encuesta de una muestra de 72 emigrantes retornados: 57 hombres y 15 mujeres. El nivel de educación más frecuente tanto en hombres como en mujeres fue en la escuela secundaria; seguido de la escuela secundaria donde la proporción de mujeres era mayor; una participación más pequeña eran los hombres y mujeres con estudios universitarios (9\%).

En este sentido, algunos autores también señalaron que, en 2015 , el $78.7 \%$ de las remesas en México se utilizaron principalmente para cubrir los gastos de alimentación y vestimenta y para tratar enfermedades, principalmente en áreas rurales. Sin embargo, las remesas $(5,6 \%)$ también se utilizaron en áreas rurales para invertir en un negocio 0 comprar algún bien o activo y el 5,7\% en educación infantil, en comparación con los habitantes de áreas urbanas (Delgado y Gaspar, 2018; Márquez, 2008, 2010).

También de acuerdo con la Encuesta sobre migración en la frontera norte de México (EMIF, 2012) las remesas que ingresaron al país en ese año se destinaron, en promedio, a gastos de consumo como alimentos y vivienda (80.3\%), para pagar deudas (46.5\%). \%), para el mantenimiento del hogar $(30.3 \%)$, para la compra de un automóvil o aparatos eléctricos (13.5\%), y sólo el $6.0 \%$ para establecer, expandir o comprar un negocio.
El Instituto Nacional de Estadística, Geografía e Informática (INEGI, 2010) también advierte que varios estudios sobre el uso de remesas familiares en México coinciden en detectar un patrón de gasto similar de los hogares que reciben remesas. Su uso se destina principalmente a satisfacer necesidades básicas que incluyen salud y educación, y un resto no mayor a diez por ciento se utiliza para ahorros o pequeñas inversiones familiares en vivienda, tierra, ganado y establecimientos comerciales.

\section{La migración de Michoacán}

Actualmente, Michoacán es una de las entidades en México que exporta la mayor cantidad de mano de obra a Estados Unidos, principalmente de campesinos que emigran en busca de medios de subsistencia y mejores niveles de bienestar que no han encontrado en sus lugares de origen. Junto con Michoacán, los estados con la mayor tasa de migración a los Estados Unidos son Guanajuato, Jalisco, México y Puebla (CONAPO 2012). En 2007, la mayoría de los migrantes de Michoacán tenían entre 16 y 35 años (68\%), individuos en etapa productiva y provenientes del campo, donde carecían de empleo y recursos para la producción agrícola, su principal actividad económica. Este hecho ha limitado el potencial productivo de las áreas rurales. Entre 1996 y 2006, las personas que emigraron tenían menos de 30 años, entre 12 y 29 años, por lo que estos jóvenes abandonaron el país con una educación truncada o incluso sin educación primaria 0 secundaria (Delgado y Gaspar, 2018).

3. Las remesas y su importancia para la economía de México, Michoacán y Huandacareo

Se ha señalado que las remesas son esenciales como fuente de divisas para los países que expulsan migrantes, pero lo hacen en términos precarios. En el caso de México, la importancia de dicho apoyo se evidencia en el hecho de que los ingresos por remesas correspondieron en 2016 al 142.9 por ciento de las exportaciones de petróleo, 136.9\% para el turismo, $100.2 \%$ de la inversión extranjera directa y 7.6 por ciento de las exportaciones no petroleras (CONAPO, 2010). 
Incluso se puede observar en la siguiente tabla que los ingresos al país por concepto de remesas familiares en el período 1990 - 2016 fue de $22.4 \%$, sólo un $13.9 \%$ por debajo de las exportaciones de petróleo, aunque estuvo por encima del ingreso proveniente de las exportaciones agrícolas, turismo y de la balanza comercial de maquiladoras. El porcentaje de remesas en el período indicado es alto, lo cual no garantiza mejoras en el desarrollo del país, ya que las remesas familiares se utilizan menos para las inversiones y la creación de empresas.
Según datos del Consejo Nacional de Población (CONAPO, 2010) Huandacareo es uno de los municipios de Michoacán con un grado muy alto de intensidad migratoria: en el año 2000 este índice era de 13,642 (ocupaba el puesto 14 en el contexto estatal de 113 municipios mientras que en 2010 se clasificó como noveno en el estado). ${ }^{2}$

Tabla 1.

México: Tipo de divisas según fuente, 1990-2016 (porcentaje)

\begin{tabular}{|c|c|c|c|c|c|c|}
\hline \multirow{2}{*}{ Periodo } & \multirow{2}{*}{$\begin{array}{l}\text { Remesas } \\
\text { familiares }\end{array}$} & \multicolumn{2}{|c|}{ Exportaciones } & \multirow{2}{*}{$\begin{array}{l}\text { Balanza comercial de } \\
\text { las maquiladora }\end{array}$} & \multirow{2}{*}{ Turismo } & \multirow{2}{*}{ Total } \\
\hline & & Petróleo & $\begin{array}{l}\text { Agricultura, ganadería y } \\
\text { pesca }\end{array}$ & & & \\
\hline $1990-1994$ & 13.1 & 36.4 & 10.8 & 20.5 & 19.3 & 100 \\
\hline $1995-1999$ & 14.6 & 29.6 & 13.2 & 26.6 & 15.9 & 100 \\
\hline $2000-2004$ & 19.7 & 29.0 & 8.1 & 31.4 & 11.9 & 100 \\
\hline $2005-2009$ & 26.8 & 43.8 & 8.0 & 10.3 & 11.1 & 100 \\
\hline 2010 - 2014 & 24.2 & 52.2 & 11.4 & 0.0 & 12.2 & 100 \\
\hline $2015-2016$ & 35.7 & 26.5 & 17.1 & 0.0 & 20.7 & 100 \\
\hline $1990-2016^{*}$ & 22.4 & 36.3 & 11.4 & 14.8 & 15.2 & 100 \\
\hline
\end{tabular}

*Promedio

Fuente: CONEVAL (2016). Disponible en: https://www.coneval.org.mx/Medicion/Documents/Indice Rezago Social_2015/Nota_Rezago_Social_2015 vf.pdf

\subsection{Situación migratoria y microempresas en Huandacareo}

La situación migratoria de Huandacareo se ha caracterizado por el constante traslado de muchos de sus habitantes a Estados Unidos con el propósito de obtener un trabajo mejor pagado, incluso cuando regresan a su comunidad de origen si es que invierten productivamente las remesas.

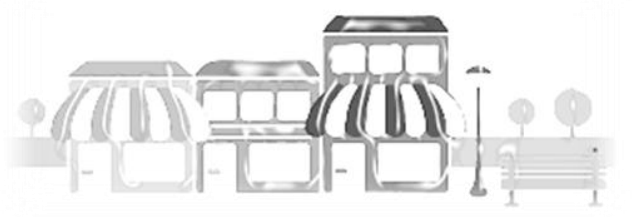

Se muestra en la tabla dos que en Huandacareo la mayoría de las microempresas se dedican al comercio minorista y

2 El Índice de Rezago Social considera información referente a la educación, el acceso a los servicios de salud, la calidad de la vivienda, los servicios básicos en la vivienda y los activos de la vivienda a través de once indicadores asociados a las diferentes dimensiones. Una vez que se tienen estas variables para cada unidad de observación (las entidades y los municipios) se procede a hacer el análisis de componentes principales y obtener un solo índice para cada unidad de observación. Finalmente, la CONAPO (2016:3) utiliza una metodología que asegura que la varianza sea la mínima al interior de cada estrato, se crean cinco grupos que dan cuenta del nivel de rezago social de cada unidad de observación. Estos grupos se clasificaron como grados de rezago social "Muy bajo", "Bajo", "Medio", "Alto" y "Muy alto". 
mayorista y a la prestación de servicios. En los años 1998, 2008 y 2014 , el $53 \%$, el 55,3 y el $50 \%$ de las empresas registradas por el INEGI se dedicaban al comercio, respectivamente (Márquez, 2010). En los censos económicos de esos tres años se informa un aumento de 73 en el número de empresas ocupadas en la prestación de servicios; mientras que el número de unidades económicas dedicadas a la agricultura disminuyó, aunque las destinadas a actividades industriales se mantuvo constantes.

Tabla 2. HUANDACAREO: TOTAL DE PEQUEÑAS Y MEDIANAS EMPRESAS SEGÚN LOS CENSOS ECONÓMICOS DE 1998, 2008 Y 2014

\begin{tabular}{|c|c|c|c|c|c|c|}
\hline \multirow[t]{2}{*}{ Sector económico / años / empresas } & \multicolumn{2}{|c|}{1998} & \multicolumn{2}{|c|}{2008} & \multicolumn{2}{|c|}{2014} \\
\hline & $\begin{array}{c}\text { Total de } \\
\text { unidades } \\
\text { económicas }\end{array}$ & $\begin{array}{l}\text { \% Unidades } \\
\text { económicas }\end{array}$ & $\begin{array}{l}\text { Total de unidades } \\
\text { económicas }\end{array}$ & $\begin{array}{l}\text { \% Unidades } \\
\text { económicas }\end{array}$ & $\begin{array}{l}\text { Total de unidades } \\
\text { económicas }\end{array}$ & $\begin{array}{l}\text { \% Unidades } \\
\text { económicas }\end{array}$ \\
\hline Comercio (mayoreo y menudeo) & 211 & 52.5 & 239 & 55.3 & 253 & 50.3 \\
\hline Servicios & 118 & 29.4 & 137 & 31.7 & 191 & 38.0 \\
\hline Industria & 56 & 13.9 & 47 & 10.9 & 56 & 11.1 \\
\hline Agricultura & 17 & 4.2 & 9 & 2.1 & 3 & 0.6 \\
\hline Total & 402 & 100 & 432 & 100 & 503 & 100 \\
\hline
\end{tabular}

Fuente: Elaboración propia con base en los Censos Económicos, INEGI.

3.2 Remesas en el municipio de Huandacareo:

Debido al creciente número de migrantes de Michoacán a los Estados Unidos, ya sea de manera permanente 0 circular, se crea un vínculo transnacional importante mediante el envío de remesas familiares o colectivas que podrían beneficiar a las comunidades de origen del migrante. Si bien las remesas se han vuelto muy importantes en los últimos 15 años, parece que se han convertido en una estrategia fundamental para el desarrollo económico, regional y local en Michoacán. Sin embargo (Neyra 2011) señaló que la dependencia de las remesas es un signo que implica el subdesarrollo, ya que las remesas como transferencias no se traducen en la creación de capacidades productivas nacionales, regionales o locales. Por lo tanto, no se puede suponer que las remesas constituyan un fondo de inversión social que mejore el desarrollo local, regional o nacional.
Además, en los últimos años en Michoacán hay problemas con el envío de remesas principalmente porque un sector de la población ya no envía remesas a la entidad porque toda su familia radica en Estados Unidos; y, en segundo lugar, en algunos casos los recursos se envían de manera especial o temporal a familiares 0 amigos que permanecen en Huandacareo. Se podría considerar que de las regiones de Michoacán la zona de Tierra Caliente, han recibido el mayor porcentaje de remesas (31\%), seguida de la zona Sierra - Costa (19.6\%); en contraste con las áreas de Tepalcatepec (11.9\%), Pátzcuaro - Zirahuen (11\%) y Purépecha $(9.3 \%)$. Huandacareo pertenece a la región de Cuitzeo y la recepción de remesas a esa ciudad está por debajo del promedio del área a la que pertenece, tanto en el período 2014 - 2017 como de enero a junio de 2017 y 2018 (tabla tres). 
ISSN: 1794-9920 Impreso / Electrónico 2500-9338

Agosto - Diembre de 2019 - Volumen 19 Número 2, Año 2019 Págs. 51 - 62

Tabla 3.

MICHOACÁN: REMESAS SEGÚN REGIÓN Y HUANDACAREO, TASA DE CRECIMIENTO 2014 - 2017 MILLONES DE DÓLARES, ABRIL - JUNIO, 2017 Y 2018

\begin{tabular}{|c|c|c|c|c|}
\hline \multirow{2}{*}{ Región* } & \multirow{2}{*}{$2014-2017^{\text {** }}$} & \multicolumn{2}{|c|}{ Millones de dólares } & \multirow{2}{*}{$2017-2018^{* * *}$} \\
\hline & & Ene-jun 2017 & Ene-jun 2018 & \\
\hline Cuitzeo & 13.5 & 260.7 & 318.6 & 18.2 \\
\hline Tierra Caliente & 31.0 & 68.2 & 80.0 & 14.8 \\
\hline Lerma-Chapala & 16.2 & 226.9 & 265.3 & 14.5 \\
\hline Pátzcuaro - Zirahuén & 11.0 & 71.3 & 82.4 & 13.5 \\
\hline Sierra-Costa & 19.6 & 51.6 & 59.4 & 13.1 \\
\hline Bajio & 16.2 & 262.0 & 300.5 & 12.8 \\
\hline Purépecha & 9.3 & 124.1 & 134.1 & 7.5 \\
\hline Oriente & 12.2 & 181.8 & 192.2 & 5.4 \\
\hline Infiernillo & 15.8 & 41.9 & 43.3 & 3.2 \\
\hline Tepalcatepec & 11.9 & 175.2 & 164.7 & -6.4 \\
\hline Huandacareo & 8.1 & 13.6 & 16.2 & 16.1 \\
\hline Michoacán & 10.6 & $1,463.7$ & $1,640.6$ & 10.8 \\
\hline
\end{tabular}

*La regionalización de los municipios de Michoacán se tomó de http://WWw.inafed.gob.mxworkJenciclopedia/EMM16michoacan/regionalizacion.html.

** Tasa de crecimiento del periodo

***Tasa de crecimiento enero-julio, Tasa de crecimiento enero-junio 2017 y 2018.

Fuente: Elaboración propia con base en Banco de México. Disponible en https://ww/vi.banxico.org.mx

\section{METODOLOGIA:}

Como se mencionó en la introducción, para detectar el número de empresas creadas con remesas se identificaron, a través del Directorio Nacional de Estadísticas de Unidades Económicas (DENUE), 152 microempresas dedicadas al comercio ubicadas en el centro de Huandacareo, diez empresas que brindan servicios de entretenimiento cultural y deportivo y otras actividades recreativas. De dicha muestra, a través de un conteo se encontró que el 72 por ciento utilizó capital distinto de las remesas para su creación, el $4 \%$ respondió positivamente al uso de remesas para fundar el negocio y el $24 \%$ no respondió.

\section{RESULTADOS:}

Debido al número de empresas creadas con remesas se cambió la estrategia de investigación original de encuestas y entrevistas breves a historias de vida, resultados que se abordan en esta sección.
Entrevista 1: Juan Díaz, propietario de una sombrerería

El señor Juan cuenta: soy originario de esta localidad, comencé a trabajar a los 15 años, por ello no puede terminar de estudiar y dejé la preparatoria; a esa misma edad decidí emigrar a los Estados Unidos y duré mucho tiempo por allá como indocumentado hasta que pude conseguir papales para entrar legalmente y poder ir constantemente a los Estados Unidos para trabajar por temporadas. Soy un hombre casado y de mi dependen económicamente 4 personas, por lo que tenía que enviar dinero cada mes a mi familia. Debido a la difícil situación que vivía en Estados Unidos en 2002, el Sr. Díaz regreso a Huandacareo e instaló una sombrerería en asociación con su hermano y con la ayuda de los envíos de dinero tanto de su hermano, como lo que él enviaba cada vez que iba a Estados Unidos. Así, ambos pusieron ese negocio en busca de autoempleo para así tener una fuente propia de ingresos. Cuando la sombrerería estuvo bien establecida, establecieron un negocio de alimento para bovinos y porcinos, éste también con la ayuda del dinero que mi hermano como socio enviaba de Estados Unidos y mi aportación. Yo atiendo los dos negocios pues mi hermano va más seguido a los Estados Unidos y temporadas más largas. Actualmente los dos negocios ya no necesitan de las remesas para seguir funcionando pues los ingresos del Sr. Díaz y su hermano permiten que sigan en marcha y son fuente de empleo. 
Entrevista 2: Sra. Angelita, propietaria de una zapatería

Soy originaria de esta localidad, soy viuda y tengo 60 años, sólo termine la primaria pues mis papás no pudieron meterme a la secundaria; me case muy joven y tuve 2 hijos. Mis hijos tampoco pudieron terminar sus estudios por falta de dinero por lo que decidieron ponerse a trabajar, a los 14 años se fueron a los Estados Unidos por falta de trabajo aquí y de dinero para sobrevivir. Tiempo después, cuando se establecen en Estados Unidos y consiguen papeles de residentes me enviaron dinero para que pusiera un negocio que me permitiera mantenerme, por eso es por lo que puse esta zapatería. Ya actualmente mis hijos no me envían dinero pues ya tienen familia, yo intento mantener el negocio porque es mi fuente de dinero, pero no es redituable, las ventas que tengo apenas alcanzan para mantenerlo.

\section{Entrevista 3: Balneario "El Edén"}

Este balneario es propiedad de la familia Díaz Vega y fue establecido con 10 socios, entre ellos primos y hermanos. Los señores Octavio y Armando cuentan que para el establecimiento de dicho balneario dependieron de la recepción de remesas de parte de los socios y ellos mismos que emigraron a los Estados Unidos. Inicialmente dependían de la crianza de ganado y cerdos, al ser insuficiente deciden cada uno por su cuenta, emigrar a los Estados Unidos en busca de una mejor vida y enviaban dinero mensualmente a sus familias. Posteriormente, en 1994 en asociación con primos y hermanos crean el balneario "El Edén" con ayuda de las remesas que recibían de los que decidieron hacerse socios y del dinero que ellos mismos habian ahorrado durante su estancia en Estados Unidos. Hoy día, el balneario continúa sosteniéndose con las remesas de los socios y también con el acceso a préstamos bancarios. Para atender y mantener el balneario tienen cinco empleados (sin contar a los propietarios quienes también trabajan ahí). De ellos, tres empleados son familiares y todos gozan de un sueldo.

\section{Entrevista 4: Balneario "Los Arcos"}

El señor Manuel Marines es originario de la localidad de Huandacareo. Cuenta que debido a la difícil situación tuvo que abandonar la escuela, pero aprendió a leer y escribir; a los 15 años emigra a los Estados Unidos en busca de empleo mejor pagado, y ya establecido y con trabajo envía dinero a sus familiares cada 15 días (2 dependientes económicos) con la finalidad de que fuera suficiente para su manutención. En 1987 vuelve a Huandacareo, y es entonces que él y sus hermanos encuentran agua caliente en los terrenos de su propiedad que utilizaban para la crianza de algunas reces. Debido a ello, deciden establecer un balneario para aprovechar el yacimiento de aguas termales en su propiedad. El Balneario lo establecen entre cinco hermanos, con el uso de remesas, es decir, sus hermanos le enviaron dinero para establecer el balneario y continuar manteniéndolo; él mismo iba a trabajar por temporadas para contribuir monetariamente. Hoy día, el negocio ya permite mantenerse solo, e incluso contratar a cinco empleados, de los cuales sólo dos no son familiares, además de trabajar en el balneario los socios 0 en su caso los descendientes de los socios (de algunos ya fallecidos). Así, con el uso de remesas, la Familia Zavala, estableció uno de los balnearios más reconocidos en Huandacareo, lugar que cuenta con siete balnearios establecidos en la localidad.

\subsection{Análisis:}

Para este estudio se consideró que la recepción de remesas familiares contribuiría al crecimiento tanto en el ámbito personal (familiar) como en el económico y local, siempre y cuando se utilizaran de manera productiva, ya sea a través de la inversión en bienes duraderos, educación y en el establecimiento de microempresas o empresas pequeñas.

Los microempresarios de Huandacareo que señalaron que sus negocios se establecieron con el uso de remesas señalaron que se generaba el autoempleo, aunque también los pequeños empresarios necesitaban asociarse con familiares que viven en Estados Unidos. Si bien los balnearios de aguas termales en Huandacareo son una parte fundamental de la economía, ya que fomentan el consumo local y de los turistas, no parecen ser una fuente de empleo para los habitantes.

Ahora bien, las personas entrevistadas tienen ciertas características comunes: nivel educativo bajo o nulo; vivían en una situación de pobreza, principalmente alimentaria durante su infancia y adolescencia; empezaron a trabajar desde muy temprana edad para mantenerse a sí mismos; tienen una historia de migración en la familia; inician un negocio para mantenerse económica y financieramente y poder regresar definitivamente a su hogar y lo hacen después de cumplir 15 años 0 más de vivir en Estados Unidos.

No obstante, se afirma que en Huandacareo la creación de empresas observada desde las últimas tres décadas es producto del aumento acelerado de la migración a los Estados Unidos y el envío de remesas. Así, el aumento del flujo monetario desde el exterior podría haber aumentado el poder adquisitivo de sus habitantes, lo que generó mayores expectativas y horizontes de servicios educativos, alimentación, salud y de otro tipo para los habitantes. 
De hecho, al tomar el grado de rezago social del municipio para el período 2000 - 2015, se muestra que, en general, el atraso social ha disminuido y ha sido bajo o muy bajo desde el año 2000 (tabla cuatro). En el campo de la educación, es notorio que los porcentajes de la población de 15 años o más analfabeta se han reducido; el de seis a 14 años que no asiste a la escuela, así como las personas con 15 años 0 más con educación básica incompleta también ha disminuido. Asimismo, para 2015, el porcentaje

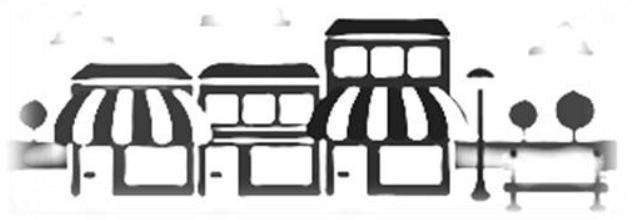
de habitantes que no tenían derecho a servicios de salud era menor $y$, de manera similar, con respecto a las condiciones de vivienda, en ese año se redujo el porcentaje de personas con casas menos equipadas (sin drenaje, agua corriente y electricidad).

\begin{tabular}{|c|c|c|c|c|}
\hline \multicolumn{5}{|c|}{$\begin{array}{c}\text { Tabla } 4 . \\
\text { HUANDACAREO: ÍNDICES DE REZAGO SOCIAL, } 2000 \text { - } 2015 \text { (PORCENTAJES) }\end{array}$} \\
\hline Conceptos\Años & 2000 & 2005 & 2010 & 2015 \\
\hline Población total & 11,808 & 11,053 & 11,592 & 11,723 \\
\hline Grado de rezado social & Bajo & Bajo & Muy Bajo & Bajo \\
\hline \multicolumn{5}{|l|}{ Escolaridad } \\
\hline Población de 15 años o más analfabeta & 18.23 & 17.26 & 12.26 & 11.52 \\
\hline Población de 6 a 14 años sin educación escolar & 13.26 & 7.62 & 4.75 & 3.00 \\
\hline $\begin{array}{l}\text { Población de } 15 \text { años o más con educación básica } \\
\text { incompleta }\end{array}$ & 76.93 & 71.09 & 66.24 & 63.00 \\
\hline \multicolumn{5}{|l|}{ Salud } \\
\hline Población sin derechohabiencia & 87.13 & 84.73 & 45.45 & 23.58 \\
\hline \multicolumn{5}{|l|}{ Vivienda } \\
\hline Hogares con piso de tierra & 10.99 & 9.22 & 5.47 & 3.27 \\
\hline Hogares sin escusado & 8.20 & 3.83 & 1.60 & 1.79 \\
\hline Hogares sin agua entubada de la red pública & 1.61 & 0.83 & 0.97 & 0.45 \\
\hline Hogares sin drenaje & 7.30 & 3.87 & 1.45 & 1.87 \\
\hline Hogares sin electricidad & 1.83 & 1.38 & 0.60 & 0.24 \\
\hline Hogares sin lavadora de ropa & 53.67 & 42.94 & 34.73 & 27.79 \\
\hline Hogares sin refrigerador & 29.39 & 16.34 & 11.38 & 7.35 \\
\hline
\end{tabular}




\section{CONCLUSIONES:}

En este estudio se observó que la proporción de la inversión productiva de las remesas para la creación de micro y pequeñas empresas en Huandacareo es muy pequeña, aunque parece que ha influido positivamente en el crecimiento económico de la localidad, ya sea directa 0 indirectamente. Por ejemplo, los balnearios representan una importante fuente de ingresos para el municipio porque son una de las principales atracciones turísticas de la región y, por lo tanto, se han creado algunos empleos para los habitantes y, a su vez, con la llegada de visitantes un mayor consumo en los negocios, con la consecuente reactivación de la economía de esa localidad.

Si bien el destino de las remesas es principalmente para el consumo, la construcción y la remodelación de viviendas, se debe tener en cuenta que una parte se invierte ahora en actividades como la educación superior. Además, el 57\% de los servicios de esparcimiento o recreación, como los balnearios existentes en ese municipio, se establecieron con remesas y algunos de ellos todavía los necesitan para su mantenimiento.

Por lo tanto, este artículo responde parcialmente a las dos preguntas de investigación planteadas al principio: ¿las remesas recibidas en Huandacareo tienen una influencia significativa en la economía de la localidad? ¿Es productivo el uso de remesas? Una mayor inversión de las remesas familiares en micro y pequeñas empresas podría ayudar a los migrantes a decidir regresar a su lugar de origen en un momento dado, en lugar de que el resto de la familia emigre gradualmente. Aunque estudios previos sobre esta localidad han concluido que el incremento de las remesas aumentaría el poder adquisitivo de los habitantes con lo que los flujos monetarios del exterior pueden generar mejoras educativas, alimentarias, sanitarias y de servicios para los habitantes, pues en general el atraso social del municipio ha disminuido.

\section{REFERENCIAS:}

Amuedo, C. y S. Pozo. (2006). "Remittances as insurance: evidence from Mexican immigrants", Journal of Population Economics, vol. 19, no. 2, págs. 227 254. Disponible en https://www.researchgate.net/publication/240592 92_Remittances_as_insurance_Evidence_from_ Mexican_immigrants/download. Fecha de consulta: 11 de octubre de 2017.

BBVA. (2018). Anuario de migración y remesas México, México: BBVA. Disponible en http://www.migracionyremesas.org/docs/Anuario_ Migracion_y_Remesas_2018.pdf. Fecha de consulta 5 de julio de 2018.

CONAPO. (2010). Índice de intensidad migratoria MéxicoEstados Unidos. México: CONAPO. Migración, Anexo B1. Índices de intensidad migratoria México-Estados Unidos por entidad federativa y municipio. México: CONAPO.

CONAPO. (2012). "Migración y salud, jóvenes mexicanos inmigrantes en Estados Unidos". Disponible en http://www.conapo.gob.mx. Fecha de consulta 2 de octubre de 2018.

CONEVAL (2016). Índice de rezago social 2015. Presentación de Resultados. Disponible en: https://www.coneval.org.mx/Medicion/Documents Indice_Rezago_Social_2015/Nota_Rezago_Soci al_2015 vf.pdf

Corona, M. A. (2018). "El arduo proceso de reinserción laboral de los retornados en la periferia globalizada", Economía, Sociedad y Territorio, vol. XVIII, no. 57, pp. 455-486.

Delgado, R. y S. Gaspar. (2018). "Confrontando el discurso dominante: las remesas bajo el prisma de la experiencia mexicana", REMHU, Rev. Interdiscip. Mobil. Hum., vol. 26, no. 52, págs. 243-263.

Durand, J. (1994). Más allá de la línea, México: CONACULTA. 
EMIF. (2012). Encuestas sobre Migración en las Fronteras Norte y Sur de México. Disponible en https://www.colef.mx/emif/.

Fernández, E. (2013). "Regresar a casa, a Huandacareo, Michoacán: remesas, retorno inversor y cambio social", Ra Ximhai, vol. 9, no. 1, enero - abril, págs. $121-134$.

Fuentes, Á. (2010). "Remesas y crecimiento económico (Un enfoque no econométrico)", Eco Revista Académica, no. 5, septiembre, pp. 86 - 97.

Goldring, L. (2004). "Family and Collective Remittances to Mexico: A Multi-dimensional typology", Development and Change, vol. 34, no. 4, septiembre, pág. $799-840$.

INEGI. (1999). Censo Económico 1999. México: INEGI. INEGI. (2009). Censo Económico 2009. México: INEGI. INEGI. (2015). Censo Económico 2015. México: INEGI.

INEGI. (2010). "México en cifras". Disponible en: http://www.inegi.org.mx. Fecha de consulta 25 de septiembre de 2017.

Levitt, P. (1998), "Social remittances: Migration Driven Local-Level Forms of Culturas Diffusion". The international Migration Review, vol. 32, no. 4, primavera, pág. 926 - 948.

Márquez, H. (2008). "México en vilo: desmantelamiento de la soberanía laboral y dependencia de las remesas", Papeles de POBLACIÓN, no. 58, octubre - diciembre, págs. $73-95$.

Márquez, H. (2010). "Responsabilizar a los migrantes del desarrollo: lecciones del laboratorio social zacatecano", Economía, Sociedad y Territorio, vol. X, no. 32, enero - abril. Disponible en https://est.cmq.edu.mx/index.php/est/article/view/ 154/658. Fecha de consulta 29 de septiembre de 2018.

Márquez, H. (2010). "Responsabilizar a los migrantes del desarrollo: lecciones del laboratorio social zacatecano", Economía, Sociedad y Territorio, vol. X, no. 32, enero-abril. Disponible en https://est.cmq.edu.mx/index.php/est/article/view/
154/658. Fecha de consulta 29 de septiembre de 2018.

Neira, F. (2011). "Remesas y desarrollo en Michoacán". Revista trabajo social, no. 19.

Nichols, S. (2002). "Another kind of remittance: transfer of agricultural innovation by migrants to their communities of origin", presentado en el Second Colloquium of International Migration, Mexico California, 29 de marzo, Berkeley, Universidad de California.

PNUD. (2008). Informe sobre Desarrollo Humano, Michoacán 2007. Disponible en http://hdr.undp.org/sites/default/files/idh_michoac an_2007.pdf. Fecha de consulta: 8 de octubre de 2017.

Vega, G. (2012). "Migración, clubes de migrantes y usos de las remesas: El caso del Estado de México", Suma de Negocios, vol. 3, no. 1, págs. 37-63.

World Bank. (2016). Informe anual 2016. Disponible en worldbank.org/annualreport. 